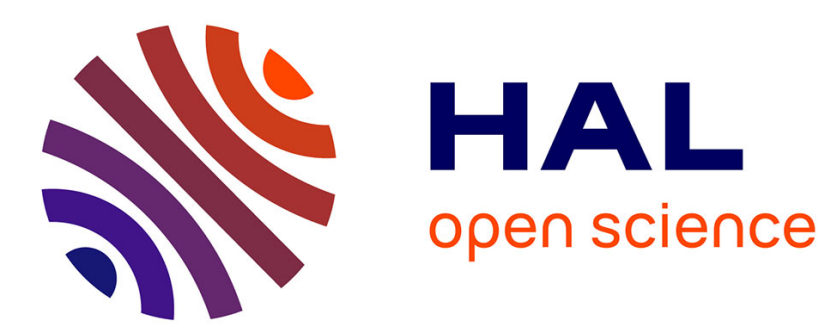

\title{
Photosensitive Titanium Oxo-polymers: Synthesis and Structural Characterization
}

Thomas Cottineau, Mireille Richard-Plouet, Annabelle Rouet, Eric Puzenat, Hari Sutrisno, Yves Piffard, Pierre-Emmanuel Petit, Luc Brohan

\section{- To cite this version:}

Thomas Cottineau, Mireille Richard-Plouet, Annabelle Rouet, Eric Puzenat, Hari Sutrisno, et al.. Photosensitive Titanium Oxo-polymers: Synthesis and Structural Characterization. Chemistry of Materials, 2008, 20 (4), pp.1421-1430. 10.1021/cm702531q · hal-02384084

\author{
HAL Id: hal-02384084 \\ https://hal.science/hal-02384084
}

Submitted on 4 Jan 2021

HAL is a multi-disciplinary open access archive for the deposit and dissemination of scientific research documents, whether they are published or not. The documents may come from teaching and research institutions in France or abroad, or from public or private research centers.
L'archive ouverte pluridisciplinaire $\mathbf{H A L}$, est destinée au dépôt et à la diffusion de documents scientifiques de niveau recherche, publiés ou non, émanant des établissements d'enseignement et de recherche français ou étrangers, des laboratoires publics ou privés. 


\title{
Photosensitive Titanium Oxo-polymers: Synthesis and Structural Characterization
}

\author{
Thomas Cottineau ${ }^{\dagger}$ Mireille Richard-Plouet, ${ }^{\dagger}$ Annabelle Rouet, ${ }^{\dagger}$ Eric Puzenat, ${ }^{\dagger,}$ \\ Hari Sutrisno, ${ }^{\dagger},{ }^{\dagger}$ Yves Piffard ${ }^{\dagger}{ }^{\dagger}$ Pierre-Emmanuel Petit, ${ }^{\dagger}$ and Luc Brohan*, ${ }^{\dagger}$ \\ Institut des Matériaux Jean Rouxel, UMR 6502 CNRS-Université de Nantes, 2 rue de la Houssinière, \\ BP 32229, 44322 Nantes Cedex 03, France, IRCELYON Institut de recherches sur la catalyse et \\ l'environnement de Lyon, UMR 5256 CNRS-Université Lyon 1, 2 Avenue Albert Einstein 69629 \\ Villeurbanne Cedex, France, and Faculty of Mathematic and Natural Sciences, Department of Chemistry, \\ University of Yogyakarta, Karangmalang, 55281 Yogyakarta, Indonesia
}

Received September 5, 2007. Revised Manuscript Received November 5, 2007

\begin{abstract}
$\mathrm{TiOCl}_{2}$ acid solution hydrolyzes $\mathrm{N}, \mathrm{N}$-dimethylformamide (DMF) at room temperature, leading to the formation of dimethylammonium chloride $(\mathrm{DMACl})$ and methanoic acid. During hydrolysis, a slow consumption of hydrochloric acid enables a gentle control over the inorganic polymerization. This onepot process allows the preparation of novel hybrid organic-inorganic sols and gels based on titanium oxide. The hydrolytic inorganic polymer was structurally characterized by XAS, X-ray diffraction, and TEM measurements, and a chemical composition was proposed for sol and gel, based on FT-IR, Raman spectroscopies, and ${ }^{1} \mathrm{H}$ and ${ }^{13} \mathrm{C}$ NMR experiments for the organic part. Results on the kinetics and growth mechanisms for nanostructured sols and gels based on titanium oxide are presented to explain the respective roles of $\mathrm{TiOCl}_{2}$ and DMF in this double hydrolysis reaction.
\end{abstract}

\section{Introduction}

Over the past decade, because of the potential applications in the field of environmental protection, the photochemistry of $\mathrm{TiO}_{2}$ has been a fast growing area both in terms of research and commercial activity. ${ }^{1}$ This level of research activity can be appreciated through the exponential increase in relevant research literature produced. ${ }^{2-4}$ In addition to the white pigment properties of rutile and anatase (e.g., paints and cosmetic products), titanium dioxide is used in heterogeneous catalysis and photocatalysis (water purification, air cleaning), in photoelectrochemical solar cells, for the production of hydrogen ${ }^{5}$ and electricity, ${ }^{6}$ as an active layer in the design of electrochromic devices, ${ }^{7}$ as a gas sensor, as a corrosionprotective coating, in ceramics, and in electric devices such as varistors, to name a few. But in such applications, the performance of titanium oxide could be optimized with specific nanostructural control over the morphology of the material. Under UV irradiation, an electron-hole pair is generated in $\mathrm{TiO}_{2}$. Technological devices are then based on chemical reactions that take place at the $\mathrm{TiO}_{2}$ /adsorbate interface and induced electron transfers resulting from this

* Corresponding author. E-mail: Luc.Brohan@cnrs-imn.fr. Tel: 3324037

39 35. Fax: 33240373995.

* Université de Nantes.

* Université Lyon 1.

${ }^{\S}$ University of Yogyakarta.

(1) Mills, A.; Lee, S.-K. J. Photochem. Photobiol. A 2002, 152, 233.

(2) Blake, D. M. Report NREL/TP-570-26797; National Renewable Energy Laboratory: Golden, CO, 1999; www.osti.gov/bridge.

(3) Dielbold, U. Surf. Sci. Rep. 2003, 48, 53.

(4) Al-Abadleh, H. A.; Grassian, V. H. Surf. Sci. Rep. 2003, 52, 63.

(5) Fujhisima, A.; Honda, K. Nature 1972, 238, 37.

(6) Grätzel, M.; O’Reagan, B. Nature 1991, 353, 737.

(7) Granqvist, C. G. Handbook of Inorganic Electrochromic Materials; Elsevier Science: Amsterdam, 1995. pair. Because of the large band gap of $\mathrm{TiO}_{2}(3.2 \mathrm{eV})$, only $10 \%$ of the solar energy is absorbed. A major objective for future work is the development of a semiconductor photocatalyst film, which would be able to utilize visible as well as UV light. Nanoscience has the potential to provide entirely new classes of materials with capabilities that transcend this limitation and generate the performance breakthroughs required for a viable economy based on sustainable energy. 8,9

Most chemical routes to $\mathrm{TiO}_{2}$ nanomaterials are based on transformations in solution such as sol-gel processing, hydroor solvothermal syntheses, metal organic decomposition (MOD), or in the vapor phase, chemical vapor deposition (CVD). Currently used precursors of titanium dioxides are molecules that already contain metal-oxygen bonds, ${ }^{10-12}$ namely, titanium alkoxides $\mathrm{Ti}(\mathrm{OR})_{4}(\mathrm{R}=$ saturated or unsaturated organic group, alkyl, or aryl), titanium oxide acetylacetonates, or titanium salts ${ }^{13-16} \mathrm{TiX}_{4}(\mathrm{X}=\mathrm{Cl}, \mathrm{Br}$, $\mathrm{NO}_{3}$ ), and the oxosalt $\mathrm{TiOSO}_{4}$. The most commonly used

(8) Dresselhaus, M. In Basic Research Needs for the Hydrogen Economy; Report of the Basic Energy Sciences Workshop on Hydrogen Production, Storage, and Use, Chicago, May 15-15, 2003; U.S. Department of Energy: Washington, D.C., 2003.

(9) Hutzler, M. J., Annual Energy Outlook 2004 with Projection to 2025; Report DOE/EIA-0383; Energy Information Administration: Washington, D. C., 2004.

(10) Ivanda, M.; Music, S.; Povavic, S.; Gotic, M. J. Mol. Struct. 1999, $645,480$.

(11) Zhong-chun, Wang; Jie-feng, Chen; Xing, Fong, Hu, Mater. Lett. 2000, $43(3), 87$.

(12) Soloviev, A.; Tufeu, R.; Sanchez, C.; Kanaev, A. V. J. Phys. Chem. B 2001, 105, 4175 .

(13) Mockel, H.; Giersig, M.; Wilig, F. J. Mater. Chem. 1999, 9, 3051.

(14) Wu, R.; Wei, Y.; Zhang, Y. Mater. Res. Bull. 1999, 34, 2131.

(15) Scolan, E.; Magneret, C.; Massiot, D.; Sanchez, C. J. Mater. Chem. 1999, 9, 2467

(16) Zhang, Q.-H.; Gao, L.; Guo, J.-K. Nanostruct. Mater. 1999, 11 (8), 1293 . 
(17) Livage, J. In Sol-Gel Technologies for Glass Producers and Users; Aegerter, M. A., Mennig, M., Eds.; Kluwer Academic: Boston, 2004.

(18) Livage, J.; Henry, M.; Sanchez, C. Prog. Solid State Chem. 1988, 18, 259.

(19) Testino, A.; Buscaglia, M. T.; Viviani, M.; Buscaglia, V.; Nanni, P. J. Am. Ceram. Soc. 2004, 87, 79.

(20) Testino, A.; Buscaglia, M. T.; Buscaglia, V.; Viviani, M.; Bottino, C.; Nanni, P. Chem. Mater. 2004, 16, 1536.

(21) Schmidt, H. J Sol-Gel Sci. Technol. 2006, 40, 1150.

(22) Brohan, L.; Sutrisno, H.; Puzenat, E.; Rouet, A.; Terrisse H. French CNRS Patent 0305619, May 9, 2003.

(23) Brohan, L.; Sutrisno, H.; Puzenat, E.; Rouet, A.; Terrisse, H. International Publication WO 2004/101436 A2, Nov 25, 2004; European CNRS patent (EP) 04742 604.4, Nov 24, 2005; Japan (JP) CNRS Patent 2006-530327, Oct 16, 2006; United States (US) CNRS Patent 018344/0578, Feb 4, 2006

(24) Brohan, L.; Sutrisno, H.; Piffard, Y.; Caldes, M.; Joubert, O. French CNRS Patent 0201055, Jan 29, 2002

(25) Brohan, L.; Sutrisno, H.; Piffard, Y.; Caldes, M.; Joubert, O.; Puzenat, E.; Rouet, A. International CNRS Patent PCT WO 03/064324 A3, Aug 07, 2003; European (EP) CNRS Patent 03734 737.4, Jan 14, 2003; Japan (JP) CNRS Patent 2003-563956, Aug 03, 2004; United States (US) CNRS Patent 2007-0041890, Feb 22, 2007. of the strong moisture sensitivity of the latter. In a typical experiment, hybrid organic-inorganic sol is usually prepared by adding droplets of DMF to an ice-cooled $\mathrm{TiOCl}_{2}$ solution to reach a titanium concentration range between 0.05 and $1.42 \mathrm{~mol} \mathrm{~L}^{-1}$ (noted $<<$ TiDMF $>>$ sol). The reaction mixture, which slowly becomes viscous, is stored in a closed container at room temperature. After aging for 13 days, the $<<$ TiDMF $>>$ sol turns into syruplike liquid and is noted $<<$ TiDMF $>>$ aged sol. Further heating at $70{ }^{\circ} \mathrm{C}$ for several hours converts the transparent sol into transparent and waxy solid, hereafter denoted $<<$ TiDMF $>>$ gel. The most common diagnostic test of gelation is to turn a test tube containing the sample upside-down and then to note whether the sample flows under its own weight. It is assumed that a sample having a yield stress (gel) will not flow, whereas a viscous but elastic sample (sol and aged sol) will show appreciable flow. ${ }^{26}$ In a typical preparation, $12 \mathrm{~mL}$ of DMF were introduced using a syringe into a closed test tube containing $5 \mathrm{~mL}$ of $4.85 \mathrm{~mol} \mathrm{~L}^{-1}$ $\mathrm{TiOCl}_{2}$ solution; the Ti concentration is thus $1.42 \mathrm{~mol} \mathrm{~L}^{-1}$. The sol was allowed to hydrolyze for $24 \mathrm{~h}$ under stirring at $25^{\circ} \mathrm{C}$, and it was then placed in an oven at $70{ }^{\circ} \mathrm{C}$ for $24 \mathrm{~h}$ to obtain the transparent gel.

Depending on the concentration, these gels can precipitate after a few days or some weeks. For a Ti concentration larger than 1.42 $\mathrm{mol} \mathrm{L}^{-1}$, an opaque white product is formed that contains a mixture of a transparent polymeric phase and an amorphous white precipitate or a white precipitate of anatase in the case of very high concentration.

FTIR and FT-Raman Absorption Spectroscopy. $<<$ TiDMF> > sol and gel were further studied by infrared and Raman spectroscopies. IR spectroscopy was performed using a FTIR Nicolet 20SXC spectrometer in the range $400-4000 \mathrm{~cm}^{-1}$. A drop of sol was deposited between two $\mathrm{KBr}$ pellets, the gel was ground with dried $\mathrm{KBr}$ and then pressed in order to obtain a pellet $(1.3 \mathrm{~cm}$ in diameter) suitable for transmission mode. In ATR mode, a slight pressure applied on sample holder allows us to distinguish the solid and liquid components of the gel.

Raman spectra were taken on a Bruker RFS 100 FT Raman spectrometer with a $1064 \mathrm{~nm}$ laser. All the samples were set in quartz Suprasil cells. The spectra were collected at room temperature with a step scan of $2 \mathrm{~cm}^{-1}$

NMR. All ${ }^{1} \mathrm{H}$ and ${ }^{13} \mathrm{C}$ NMR spectra were acquired at room temperature on an ARX spectrometer operating at $400 \mathrm{MHz}$. The recycle times used are $2 \mathrm{~s}$ for NMR ${ }^{1} \mathrm{H}$ and $50 \mathrm{~s}$ for NMR ${ }^{13} \mathrm{C}$. The last one has been fixed to obtain the good proportions between each carbon in DMF. First, ${ }^{1} \mathrm{H}$ NMR spectra were recorded separately for dimethylammonium chloride (DMACl) in aqueous solution, methanoic acid, $\mathrm{HCOOH}$, and DMF. Then, $\mathrm{HCl}$ was added to each sample in order to obtain acidic conditions close to those of $\left\langle<\right.$ TiDMF $>>$ sol $\left(\left[\mathrm{Ti}^{4+}\right]=1.42 \mathrm{~mol} \mathrm{~L}{ }^{-1}\right) . \mathrm{A}^{1} \mathrm{H}^{-13} \mathrm{C}$ correlation spectrum has been realized to attribute the peaks obtained in ${ }^{13} \mathrm{C}$ NMR. Fits of peaks were carried out with dmfit 2002 program, ${ }^{27}$ using Lorentzian curves. All solutions were maintained in darkness at room temperature, in tubes $5 \mathrm{~mm}$ in diameter. Locking was performed with a $\mathrm{D}_{2} \mathrm{O}$ set in an inner tube for the quantitative analysis, in order to prevent any perturbation of the system by this extra solvent.

XAS. XAS spectra were collected at the titanium K-edge in fluorescence mode at the Hasylab facility (Hamburger Synchrotronstrahlungslabor at DESY) on an A1 beam line, at FAME-B30B

(26) Macosko, C. W. Rheology: Principles, Measurements and Applications; VCH Publisher: New York, 1994.

(27) Massiot Hoatsonzprint, D.; Fayon, F.; Capron, M.; King, I.; Le Calvé, S.; Alonso, B.; Durand, J.-O.; Bujoli, B.; Gan, Z.; Hoatson, G. Magn. Reson. Chem. 2002, 40, 70 . 
or BM29, (ESRF, Grenoble) for EXAFS and XANES spectra of $<<\mathrm{TiDMF}>>$ sol and gel, with a seven-cell $\mathrm{Si}(\mathrm{Li})$ detector and 30- or 13-cell Ge detector, respectively. We have checked that the Ti concentration is low enough in our samples to avoid any autoabsorption corrections. The $<<$ TiDMF $>>$ sol and gel, in their oxidized state (i.e., not UV irradiated), were contained in a small Teflon cell covered with a $5 \mu \mathrm{m}$ sheet of kapton, assuring the airtightness. For EXAFS and XANES experiments performed at Hasylab, a two-crystal Si (111) monochromator was used. Harmonic rejection was carried out by detuning the second crystal to $60 \%$ of maximum transmission. At FAME, a double-crystal Si (220) monochromator was used together with two Rh-coated Si mirrors for harmonic rejection. At BM29, the monochromator was a double crystal Si (111) and harmonic rejection was performed using two $\mathrm{Si}$ mirrors. Commercial $\mathrm{TiO}_{2}$ (rutile and anatase) was mixed with the appropriate amount of boron nitride $\mathrm{BN}$ to obtain, in transmission detection, an absorption jump close to 1 across the edge. XANES spectra were normalized by assigning a value of 1 to the absorbance at half of first EXAFS oscillation. XANES peaks were extracted by fitting the background with a cubic polynomial function. The resulting peaks were fitted with a pseudovoigt function, the Gaussian part was fixed to a suitable value and not refined $(30 \%)$. The width of the peaks were refined but constrained together. For EXAFS spectra, the $k \chi(k)$ function was extracted from the absorption coefficient using a cubic spline function. ${ }^{28}$ The Fourier Transforms were performed on $k^{3} \chi(k)$ with a Kaiser-Bessel window $(\tau=3)$ in the $k$-range $4.5-12 \AA^{-1}$ for $<<$ TiDMF $>>$ gel and $5-12 \AA^{-1}$ for $<<$ TiDMF $>>$ sol. Using FEFF7 Code, ${ }^{29}$ we calculated EXAFS oscillations for different clusters corresponding to usual $\mathrm{Ti}-\mathrm{O}$ and $\mathrm{Ti}-\mathrm{Ti}$ distances, namely, in the $1.90-2.20 \AA$ range for the first shell and between 3.15 and $3.80 \AA$ for the second shell, corresponding to connection between octahedra sharing edges or corners. All the fits were undertaken with Michalowicz's EXAFS signal treatment and refinement programs. ${ }^{30}$

X-ray Diffraction (XRD). X-ray diffraction patterns of sols and gel, enclosed in a Lindeman capillary, were collected at room temperature in a Debye-Scherrer geometry using an INEL diffractometer equipped with a $120^{\circ}$ curved CPS 120 position-sensitive detector and a quartz monochromator $(\mathrm{CuK \alpha} 1$ radiation: $\lambda=$ $1.540598 \AA$ ).

TEM. The structure and morphology of sol and gel were investigated by electron microscopy. $<<$ TiDMF $>>$ sol and $<<$ TiDMF $>>$ gel, crushed beforehand in DMF, were deposited on a copper grid covered with a carbonaceous membrane allowing the observation in transmission electron microscopy. A highresolution electron microscopy (HREM) study was carried out with a Hitachi H9000NAR electron microscope operating at $300 \mathrm{kV}$ with a Scherzer resolution of $1.8 \AA$. Image calculations were performed using the MACTEMPAS program. ${ }^{31}$ To reduce irradiation damage produced by the electron beam on the sample, the size of the condenser aperture was reduced. In spite of these precautions, the observation of the samples has proved to be difficult because of the high vacuum present in the column. Therefore, a gradual transformation of $<<\mathrm{TiDMF}>>$ gel was observed in the course of the experiment. Further details will be exposed in Results and Discussion.

(28) Winterer, M. J. Phys. IV 1997, 7, C2-243.

(29) Rehr, J. J.; Mustre de Leon, J.; Zabinsky, S. I.; Albers, R. C. J. Am. Chem. Soc. 1991, 113 (14), 5135.

(30) Michalowicz, A. EXAFS pour le Mac, Logiciels pour la Chimie; Société Française de Chimie: Paris, 1991; p 102.

(31) O'Keefe, M. A.; KilaasR. MacTempas, V1.70 and Crystalkit V1.77, HRTEM Image Analysis; Lawrence Berkley National Laboratory: Berkeley, CA, 1987.

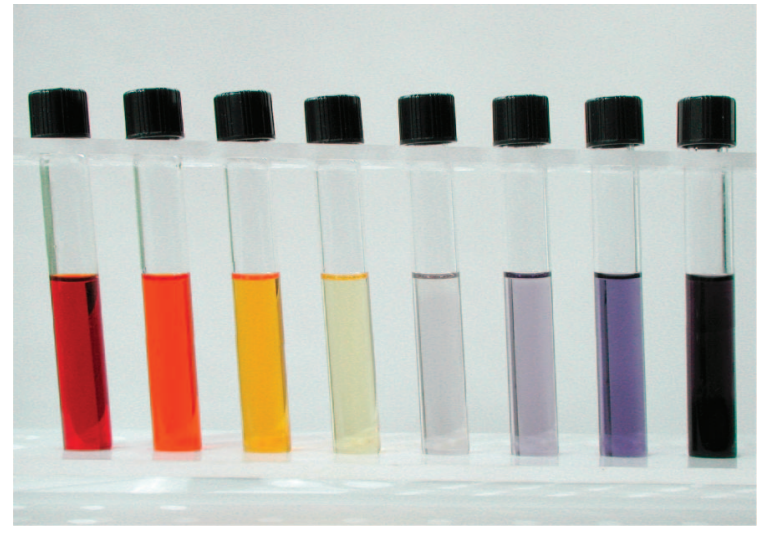

Figure 1. Coloration time dependence (red to dark blue) of $<<$ TiDMF $>>$ sols upon daylight irradiation at $300 \mathrm{~K}$.

\section{Results and Discussion}

Interestingly, these sols and gel exhibit original optical and electronic properties that will be described and discussed in a forthcoming paper. The resulting samples show high transparency and exhibit a strong red coloration upon irradiation with UV or daylight that changes to orange-yellow and finally turns dark blue after prolonged illumination, as shown in Figure 1. When UV excitation was removed, the photogenerated species exhibit a long lifetime that can reach several years in a closed test tube and at room temperature. The singular photoelectrochemical properties of nanostructured sols and gels offer new possibilities in areas such as photochemical conversion and storage of solar energy, in both third-generation photovoltaic cells and photobatteries (ultracapacitors).

The structure and chemical composition of the transparent $<<$ TiDMF $>>$ sols and gel have been investigated using several techniques according to the organic or inorganic constituents.

Characterization of the Organic Component. FT-IR and Raman Spectroscopies. Strong mineral acids are effective reagents for the hydrolysis of amides at about $100{ }^{\circ} \mathrm{C}$. The products are usually a mixture of the amine and carboxylic acid according to the following equation ${ }^{32}$

$$
\mathrm{R}_{2} \mathrm{NCHO}+\mathrm{HCl}+\mathrm{H}_{2} \mathrm{O} \rightarrow \mathrm{R}_{2} \mathrm{NH}_{2} \mathrm{Cl}+\mathrm{HCOOH}
$$

( $\mathrm{R}=\mathrm{H}$, alkyl, aryl, etc.) S. Liu et al. reported also that the hydrolysis of DMF into dimethylamine is catalyzed by polyoxometalate, 12-molybophosphate acid. ${ }^{33}$ In our experiment using $\mathrm{TiOCl}_{2}$ in DMF, because of the presence of $\mathrm{HCl}$ to stabilize the oxychloride solution, formation of dimethylammonium chloride is expected. Its presence together with methanoic acid was detected by infrared, Raman, and NMR spectroscopies.

For comparison, infrared spectra for dimethyformamide slightly hydrated, $<<$ TiDMF $>>$ sol (freshly prepared and 4 days aging) and $<<$ TiDMF $>>$ gel (heated at $70^{\circ} \mathrm{C}$ for

(32) Challis B. C.; Challis, J. A. The Chemistry of Amides; Zabicky, J., Ed.; Interscience Publishers: London, 1970.

(33) Liu, S.; Wang, C.; Zhai, H.; Li, D. J. Mol. Struct. 2003, 654, 215.

\section{7




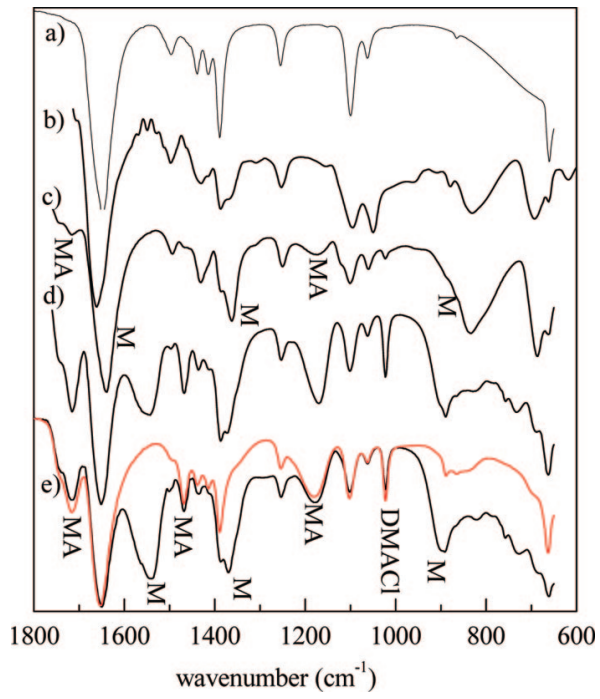

Figure 2. tk; $4 \mathrm{FTIR}$ spectra of various titanium compounds and organic species: (a) DMF $+\mathrm{H}_{2} \mathrm{O}$, (b) freshly prepared sol, (c) 4 day aged sol, (d) $<<$ TiDMF $>>$ gel, (e) liquid (red) and solid (black) part of gel (MA, methanoic acid; $\mathrm{M}$, methanoate).

(34) Nakamoto, K. Infrared and Raman Spectra of Inorganic and Coordination Compounds, 4th ed.; Wiley: New York, 1986.

(35) Colthup, N. B.; Daly L. H.; Wiberley, S. E. Introduction to Infrared and Raman Spectroscopy, 3rd ed.; Academic Press: San Diego, CA, 1990.

(36) Stalhandske, C. M. V.; Mink, J.; Sandström, M.; Papai, I.; Johansson, P. Vibr. Spectrosc. 1997, 14, 207.

(37) (a) Chang, Y.-T.; Yamaguchi, Y.; Miller, W. H.; and Schaefer, H. F.; J. Am. Chem. Soc. 1987, 109 (4). (b) Georges, R.; Freytes, M.; Hurtmans, D.; Kleiner, I.; Vander Auwera, J.; Herman, M. Chem. Phys. 2004, 305, 1870 .

(38) Walrafen, G. E.; Pugh, E. J. Sol Chem. 2004, 33 (1), 81.

(39) Combelas, P.; Costes, M.; Garrigou-Lagrange, C. Can. J. Chem. 1975, 53,442 .

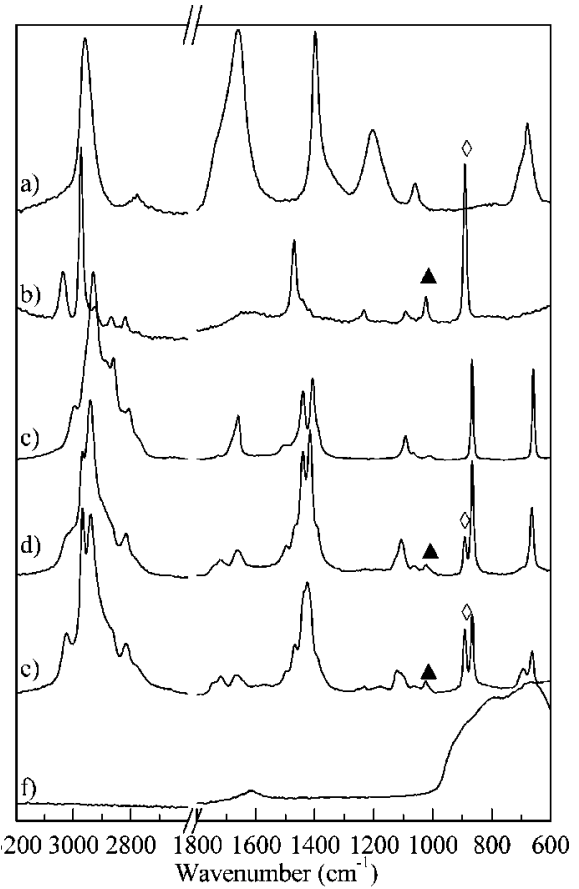

Figure 3. Raman spectra of various titanium compounds and organic species: (a) methanoic acid; (b) DMACl, $\mathbf{\Lambda}, 1022 \mathrm{~cm}^{-1}<118>\left(\mathrm{CH}_{3}\right)_{\mathrm{ip}}$; $\diamond$, $880 \mathrm{~cm}^{-1} v_{\mathrm{s}}(\mathrm{CN})$; (c) DMF; (d) $4.26 \mathrm{~mol} \mathrm{~L}^{-1} \mathrm{HCl}$ in DMF solution; (e) $1.42 \mathrm{~mol} \mathrm{~L}^{-1}<<\mathrm{TiDMF}>>$ gel; (f) $\mathrm{TiOCl}_{2}$ acid solution.

tions of methanoate ions are evidenced at $v_{\mathrm{as}}=1620 \mathrm{~cm}^{-1}$ and $v_{\mathrm{s}}=1364 \mathrm{~cm}^{-1}$ for a 4 day aged sol, whereas they are shifted to $v_{\text {as }}=1555 \mathrm{~cm}^{-1}$ and $v_{\mathrm{s}}=1373 \mathrm{~cm}^{-1}$ in the case of gel. Usually, carboxylate anions can coordinate metal cations in different ways: monodentate, bidentate (chelate), or bridging two cations. The value of $\Delta=v_{\mathrm{as}}-v_{\mathrm{s}}$ enables us to discriminate between these different complexes. ${ }^{33} \mathrm{In}$ the case of a 4 day aged sol, $\Delta=256 \mathrm{~cm}^{-1}$ is in the range of monodentate complexation, whereas in the gel, $\Delta=182$ $\mathrm{cm}^{-1}$ corresponds to a bridging or ionic carboxylate. The latter is observed only in the solid part of the gel, indicating that $\mathrm{Ti}$ atoms are complexed only in the polymerized inorganic component of the gel.

Figure 3 shows the Raman spectra of the aged sol $<<$ TiDMF $>>1.42 \mathrm{~mol} \mathrm{~L}^{-1}$ and the $(\mathrm{DMF}+\mathrm{HCl})$ solution, along with those of DMF, DMACl, and methanoic acid. For comparison, a Raman spectrum of $\mathrm{TiOCl}_{2}$ in acidic solution was also recorded. As expected, the Raman spectra of $\mathrm{DMF} / \mathrm{HCl}$ solution (Figure $3 \mathrm{e}$ ) and aged sol $<<$ TiDMF $>>$ (Figure 3d) are quite similar. They appear to consist of DMF component bands ((Figure 3c), whereas the additional peaks can be mainly assigned to methanoic acid (Figure 3a) and DMACl (Figure 3b). In comparison to pure DMF, the characteristic frequencies of $\mathrm{DMF} / \mathrm{HCl}$ and $<<\mathrm{TiDMF}>>$ are slightly shifted as already underlined from the IR study. This trend, observed for DMF in many aqueous systems, ${ }^{40,41}$ is due to water molecules coordinated to DMF molecules. The intensity of DMACl vibrations at $891 \mathrm{~cm}^{-1}\left(v_{\mathrm{s}} \mathrm{CN}\right)$ and $1022 \mathrm{~cm}^{-1}\left(\rho_{\mathrm{ip}}\left(\mathrm{CH}_{3}\right)\right)$ becomes progressively higher with increasing titanium concentration and hydrolysis spread (aged sol and gel). On 
Table 1. Assigments of ${ }^{1} \mathrm{H}$ Chemical Shifts for DMACl, $\mathrm{HCOOH}$, and DMF in Aqueous Solution, Or in the Presence of $\mathrm{HCl}$ and Assigments of ${ }^{1} \mathrm{H}$ and ${ }^{13} \mathrm{C}$ NMR Chemical Shifts for $<<$ TiDMF $>>$ Sol Aged for 2 Days

\begin{tabular}{|c|c|c|c|c|c|c|}
\hline $\begin{array}{l}{ }^{1} \mathrm{H}(\mathrm{ppm}) \\
\text { in water }\end{array}$ & $\begin{array}{l}{ }^{1} \mathrm{H}(\mathrm{ppm}) \\
\text { with } \mathrm{HCl}\end{array}$ & $\begin{array}{c}{ }^{1} \mathrm{H}(\mathrm{ppm}) \\
<<\text { TiDMF }>>\text { sol }\end{array}$ & $\begin{aligned} &{ }^{13} \mathrm{C}(\mathrm{ppm}) \\
&<<\text { TiDMF }>>\text { sol }\end{aligned}$ & DMACl & $\mathrm{HCOOH}$ & DMF \\
\hline 2.74 & 2.78 & 2.89 & 29.7 & $-\left(\mathrm{CH}_{3}\right)_{2}$ & & \\
\hline 2.85 and 3.02 & 2.96 and 3.14 & 3.10 and 3.30 & 27.1 and 32.5 & & & $-\left(\mathrm{CH}_{3}\right)_{2}$ doublet \\
\hline 5.0 & & 7.27 & & & $-\mathrm{CO}_{2} \mathrm{H}, \mathrm{H}_{2} \mathrm{O}$ & \\
\hline 8.08 & 8.17 & 8.42 & 160.1 & & & $-\mathrm{HCO}$ \\
\hline 8.25 & 8.34 & 8.51 & 158.7 & & $-\mathrm{HCO}$ & \\
\hline
\end{tabular}

the other hand, the DMF components at $663 \mathrm{~cm}^{-1}$ $\left.{ }_{\delta} \mathrm{O}=\mathrm{C}-\mathrm{N}\right)$ and $866 \mathrm{~cm}^{-1} v_{\mathrm{s}}\left(\mathrm{C}_{2}{ }_{2} \mathrm{~N}\right)$ become less dominant.

The formation of methanoic acid and dimethylammonium chloride has also been checked and quantified using proton NMR spectroscopy.

${ }^{1} \mathrm{H}$ and ${ }^{13} \mathrm{C}$ NMR Spectroscopies. Liquid ${ }^{1} \mathrm{H}$ and ${ }^{13} \mathrm{C}$ NMR spectra of $<<$ TiDMF $>>$ sol clearly show that the DMF decomposes into dimethylammonium chloride and methanoic acid. The attribution of peaks has been made by comparison with the parent phases. The ${ }^{1} \mathrm{H}$ and ${ }^{13} \mathrm{C}$ NMR chemical shifts of DMACl, $\mathrm{HCOOH}$, and DMF without addition of $\mathrm{HCl}$, are summarized in Table 1 . Figure 4, shows the spectra obtained for (a) DMACl + $\mathrm{HCl}$, (b) $\mathrm{HCOOH}+\mathrm{HCl}$, (c) $\mathrm{HCOOH}+\mathrm{DMACl}+\mathrm{HCl}$, (d) $\mathrm{DMF}+\mathrm{HCl}$, and (e) $<<\mathrm{TiDMF}>>$ sol after aging for 2 days. The peak of the $-\left(\mathrm{CH}_{3}\right)_{2}$ protons of DMACl is split into a triplet because of the multiplicity rule of the signals: such protons are coupled with the two protons of $-\mathrm{NH}_{2}{ }^{+}$. The addition of $\mathrm{HCl}$ to DMACl (Figure 4a) and $\mathrm{HCOOH}$ (Figure 4b) slightly affects the signals with respect to those observed without acid. In the DMACl + $\mathrm{HCOOH}+\mathrm{HCl}$ spectrum (Figure 4c), peaks characteristic of the protons of DMACl and $\mathrm{HCOOH}$ appear as well as those corresponding to the protons of $\mathrm{H}_{3} \mathrm{O}^{+}, \mathrm{NH}_{2}{ }^{+}$, and $\mathrm{H}_{2} \mathrm{O}$. A comparison of this spectrum with that of DMF + $\mathrm{HCl}$ (Figure 4d) confirms that the hydrolysis reaction of DMF in acidic medium led to the formation of methanoic

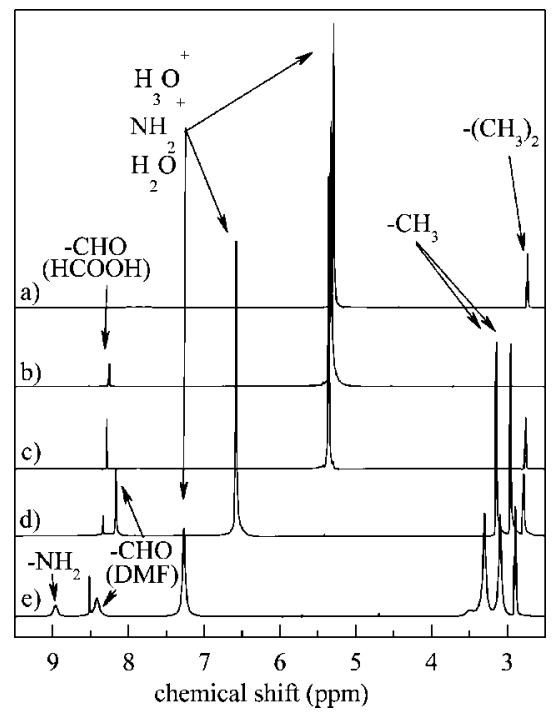

Figure 4. ${ }^{1} \mathrm{H}$ NMR spectra of various mixtures: (a) dimethylammonium chloride (DMACl) and $\mathrm{HCl}$; (b) methanoic acid and $\mathrm{HCl}$; (c) DMACl, methanoic acid, and $\mathrm{HCl}$; (d) dimethylformamide (DMF) and $\mathrm{HCl}$; (e) $<<\mathrm{TiDMF}>>$ sol aged for 2 days, containing $\mathrm{TiOCl}_{2} \cdot 1.4 \mathrm{HCl}, 7 \mathrm{H}_{2} \mathrm{O}$, and DMF with concentration $\left[\mathrm{Ti}^{4+}\right]=1.42 \mathrm{~mol} \mathrm{~L}{ }^{-1}$. acid and dimethylammonium chloride. Indeed, six peaks can be distinguished in spectrum $\mathrm{d}$. Their position and attribution are summarized in Table 1, together with the results for $<<$ TiDMF $>>$ sol. In the ${ }^{1} \mathrm{H}$ NMR spectrum of $<<$ TiDMF $>>$ sol (Figure $4 \mathrm{e}$ )), peaks characteristic of $\operatorname{DMF}(3.10,3.30$, and $8.42 \mathrm{ppm}), \mathrm{DMACl}(2.89 \mathrm{ppm})$, and $\mathrm{HCOOH}(8.51 \mathrm{ppm})$ are clearly evident. The relative surface area between the methyl groups of DMF and those of DMACl accounts for the progress of the hydrolysis reaction of DMF (at this stage, a small amount of DMF is hydrolyzed). However, some significant differences were evidenced. The peak of the $-\mathrm{NH}_{2}{ }^{+}$protons appears only in the $<<$ TiDMF $>>$ sol spectrum at $8.96 \mathrm{ppm}$ (and not in the DMACl spectrum or DMACl $+\mathrm{HCl}$ spectrum). This could be explained by the difference between solution concentrations and/or to the presence of inorganic species. For the DMACl spectrum, the DMACl is diluted in water (and $\mathrm{HCl}$ ) and thus less concentrated than in the DMF + $\mathrm{TiOCl}_{2}$ solution. In this case, it is considered that the $-\mathrm{NH}_{2}{ }^{+}$protons have the same chemical shifts as $\mathrm{H}_{2} \mathrm{O}$ (and $\mathrm{H}_{3} \mathrm{O}^{+}$) protons. Furthermore, a shift of the peak related to protons $\mathrm{H}_{3} \mathrm{O}^{+}$is observed (due to dilution with $\mathrm{D}_{2} \mathrm{O}$ for signal locking) together with a broadening of the peaks of the $-\mathrm{CHO}$ protons of DMF.

For the ${ }^{13} \mathrm{C}$ NMR spectrum of $<<$ TiDMF $>>$ sol aged for 2 days (Figure S1 in the Supporting Information), the peaks located at 160.1, 32.5, and $27.1 \mathrm{ppm}$ are assigned to DMF, C of the aldehyde group and C of methyl, respectively, whereas those located at 29.7 and $158.7 \mathrm{ppm}$ are characteristic for $\mathrm{DMACl}$ and $\mathrm{HCOOH}$, respectively.

Quantitative Analysis of «TiDMF»Sol-Gel Formation. It is possible to follow the kinetic evolution of the DMF hydrolysis by estimating the amount of the various products from ${ }^{1} \mathrm{H}$ or ${ }^{13} \mathrm{C}$ NMR and Raman spectroscopies.

The normalized amount of DMACl, calculated either from the ${ }^{1} \mathrm{H}$ or ${ }^{13} \mathrm{C}$ spectra, is determined by the ratio between the $-\mathrm{CH}_{3}$ peak areas (at 2.89 and $29.7 \mathrm{ppm}$ for ${ }^{1} \mathrm{H}$ and ${ }^{13} \mathrm{C}$ spectra, respectively) of DMACl, and the area of the $-\mathrm{CH}_{3}$ peaks related to the DMF $+\mathrm{DMACl}$ components. Similarly, the quantity of methanoic acid can also be evaluated by the ratio between the area of the peak at $8.51 \mathrm{ppm}$ and the area of the peaks at 8.51 and $8.42 \mathrm{ppm}$ in the ${ }^{1} \mathrm{H}$ spectrum and area of the peak at 158.7 ppm divided by the area of the peaks at 158.7 and 160.1 $\mathrm{ppm}$ in the ${ }^{13} \mathrm{C}$ spectrum. From these data, the evolution of the concentration in DMF can be plotted (Figure $5($ left)). After 56 days, the sol becomes very viscous and no signal is detectable with the liquid NMR conditions. The amount of consumed DMF corresponds to $36 \%$ of 


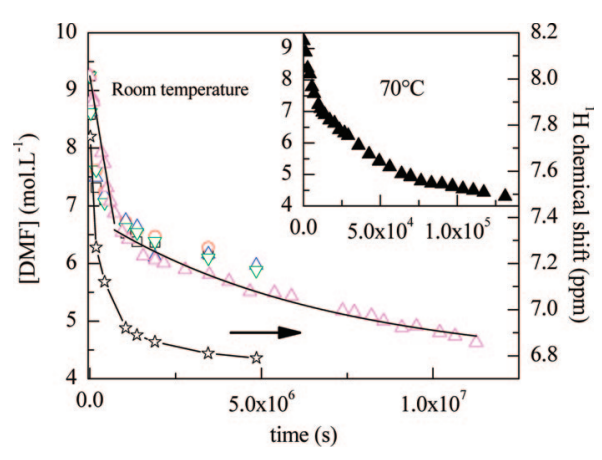

Figure 5. Kinetics of DMF hydrolysis at room temperature (left scale) determined by ${ }^{1} \mathrm{H}$ and ${ }^{13} \mathrm{C}$ NMR $\left({ }^{1} \mathrm{H}\right.$ from $\square, \mathbf{H C O O H}$ peak at $8.28 \mathrm{ppm}$; $\left.\mathrm{O}, \mathrm{CH}_{3}\right)_{2} \mathrm{NH}_{2} \mathrm{Cl}$ peak at $2.69 \mathrm{ppm}$; and ${ }^{13} \mathrm{C}$ from $\triangle, \mathrm{HCOOH}$ peak at 158.7 ppm; $\nabla,\left(\mathrm{CH}_{3}\right)_{2} \mathrm{NH}_{2} \mathrm{Cl}$ peak at $\left.29.7 \mathrm{ppm}\right)$ and by Raman spectroscopy $(\triangle$, $v_{\mathrm{S}}(\mathrm{CN})_{\mathrm{DMACl}} / v_{\mathrm{S}}\left(\mathrm{C}_{2}^{\prime} \mathrm{N}\right)_{\mathrm{DMF}}$ surface area ratio), reduction in acidity ( $\vec{w}$, right scale), for $\mathrm{TiOCl}_{2} / \mathrm{DMF}$ sol with concentration $\left[\mathrm{Ti}^{4+}\right]=1.42 \mathrm{~mol} \mathrm{~L}^{-1}$. Inset: at $70{ }^{\circ} \mathrm{C}$ for the same $<<$ TiDMF $>>$ sol and deduced from Raman experiments.

the initial content, at room temperature. The global reaction can thus be written

$\mathrm{TiOCl}_{2} \cdot 1.4 \mathrm{HCl} \cdot 7 \mathrm{H}_{2} \mathrm{O}+$

$$
\begin{aligned}
& x\left(\mathrm{CH}_{3}\right)_{2} \mathrm{NCHO} \rightarrow \text { " } \mathrm{TiO}_{2}, z \mathrm{H}_{2} \mathrm{O} \text { polymer" }+ \\
& y\left(\mathrm{CH}_{3}\right)_{2} \mathrm{NH}_{2} \mathrm{Cl}+y \mathrm{HCOOH}+(x-y)\left(\mathrm{CH}_{3}\right)_{2} \mathrm{NCHO}+ \\
& (3.4-y) \mathrm{HCl}+(6-y-z) \mathrm{H}_{2} \mathrm{O}
\end{aligned}
$$

With $x=6.4$ and $y=2.3$ at the end of this experiment for $\left[\mathrm{Ti}^{4+}\right]=1.42 \mathrm{~mol} \mathrm{~L}^{-1}$.

Furthermore, the time evolution of the acidity in the solution was followed by plotting the chemical shift of the peak of the acidic protons $\left(\mathrm{H}_{3} \mathrm{O}^{+}, \mathrm{NH}_{2}{ }^{+}\right)$group in ${ }^{1} \mathrm{H} \mathrm{NMR}$ spectra. The quantity of $\mathrm{HCl}$ consumed during the acidobasic reaction induces a decrease in acidity of the medium. This is reflected in ${ }^{1} \mathrm{H}$ NMR spectra by a decrease in the chemical shift of $\mathrm{H}_{3} \mathrm{O}^{+}$ions (放, Figure 5(right). Interestingly, the increased $\mathrm{pH}$ value has a direct consequence on polycondensation of inorganic species: the stability of $\mathrm{TiOCl}_{2}$ is altered and an inorganic condensation can occur. As evidence on XAS experiments, the $\mathrm{TiOCl}_{2}$ solution is hydrolyzed into polymeric form of titanium oxides, which is schematically summarized by the reactions

$$
\begin{gathered}
\mathrm{TiOCl}_{2}+2 \mathrm{H}_{2} \mathrm{O} \rightarrow \mathrm{TiO}(\mathrm{OH})_{2}+2 \mathrm{HCl} \\
\mathrm{TiO}(\mathrm{OH})_{2},(z-1) \mathrm{H}_{2} \mathrm{O} \rightarrow{ }^{\circ} \mathrm{TiO}_{2}, z \mathrm{H}_{2} \mathrm{O} \text { polymer" }
\end{gathered}
$$

Raman spectroscopy was also undertaken to quantify the advancement of hydrolysis because the $v_{\mathrm{s}}(\mathrm{CN})$ vibration of dimethylammonium chloride $\left(891 \mathrm{~cm}^{-1}\right)$ and $\nu_{\mathrm{s}}\left(\mathrm{C}_{2}^{\prime} \mathrm{N}\right)$ of dimethylformamide $\left(866 \mathrm{~cm}^{-1}\right)$ are well-separated and their relative surface areas are proportional to the $\left(\mathrm{CH}_{3}\right)_{2} \mathrm{NH}_{2} \mathrm{Cl} /$ DMF molar ratio. This assertion has been confirmed by recording reference spectra of $\left(\mathrm{CH}_{3}\right)_{2} \mathrm{NH}_{2} \mathrm{Cl}$ mixed with DMF in a different ratio. To determine this area, we fitted the peaks by a pseudo Voigt function (50\% Gaussian) after removing the background. The results for sols that were aged for various times and for gels are also gathered in Figure 5(left), together with the NMR results. The evolution of the DMF concentration could be followed on a longer duration. In addition, we could get additional information on the gel that was not available with the liquid NMR study. The hydrolysis extent reaches more than $50 \%$ in agreement with the stoichiometric proportion, which is close to the maximum (53\% with $x=6.4, y=3.4, z \leq 2.6$ ), as shown in eq 2. At equilibrium, all hydrochloric acid of $\mathrm{TiOCl}_{2}$ solution is released, leading to the hydrolysis of DMF and the formation of dimethylammonium chloride and methanoic acid. The decrease in DMF concentration can be accounted for with a linear variation ( 0 order kinetics) during the first 8 days and then with an exponential decay (first order kinetics). The kinetics of gelation can be significantly accelerated by an annealing treatment at $70{ }^{\circ} \mathrm{C}$. Figure 5 (inset) shows the ex situ evolution of the $\left(\mathrm{CH}_{3}\right)_{2} \mathrm{NH}_{2} \mathrm{Cl} / \mathrm{DMF}$ molar ratio inferred from Raman experiments. The induction time for gelation is reduced by about 2 orders of magnitude because the sol-gel transformation operates after $36 \mathrm{~h}$, whereas at room temperature, a gel may be obtained within 7 months. It is worth noting that during this discontinuous thermal treatment, required for the ex situ measurements, the gelation time is longer compared with that of the continuous reaction (24 h).

Characterization of the Inorganic Component. From the above IR, Raman, and NMR studies of $<<$ TiDMF $>>$ sols and gels, it is found that the hydrolysis of DMF solvent into DMACl and methanoic acid is catalyzed by the $\mathrm{TiOCl}_{2}$ acid solution. Without stirring and annealing, the hydrolysis process is limited by the diffusion rate and proceeds slowly over several days, in such a way that the various steps of the inorganic polymerization can be easily controlled. The induced gelation phenomena have been investigated by XAS, $\mathrm{X}$-ray diffraction, and TEM analysis.

XAS Experiments. The local arrangements of $<<$ TiDMF $>>$ polymeric sols and gel around $\mathrm{Ti}$ atoms were characterized by analysis of the XAS signal recorded at the titanium $\mathrm{K}$-edge. The structure of the inorganic polymer mainly depends on the initial titanium concentration and on the hydrolytic conditions, especially the aging and thermal treatment. Prior to the EXAFS signal being analyzed, information concerning the local symmetry around Ti atoms can be inferred from the XANES spectrum and particularly from the pre-edge structure analysis (figure 6).

At the titanium K-edge, freshly prepared sol, matured sol, and gel present three pre-edge peaks in agreement with $\mathrm{Ti}$ atoms located in an octahedral environment. ${ }^{42}$ In the case of freshly prepared sols, these three peaks are decomposed into three contributions: for a sol with $\left[\mathrm{Ti}^{4+}\right]=0.1 \mathrm{~mol} \mathrm{~L}^{-1}$, A1 is located at $4968.7 \mathrm{eV}, \mathrm{A} 3$ at $4970.8 \mathrm{eV}$, and finally, B at $4973.2 \mathrm{eV}$; for a sol with $\left[\mathrm{Ti}^{4+}\right]=1.42 \mathrm{~mol} \mathrm{~L}^{-1}$, the positions are $\mathrm{A} 1$ at $4968.9 \mathrm{eV}, \mathrm{A} 3$ at $4971.0 \mathrm{eV}$, and $\mathrm{B}$ at $4973.6 \mathrm{eV}$. These three peaks are close to the positions of the pre-edge structures in rutile. A matured sol and a gel exhibit the same features, and four contributions are needed to account for the pre-edge structures: A1 located at 4968.6 $\mathrm{eV}, \mathrm{A} 2$ at $4970.4 \mathrm{eV}, \mathrm{A} 3$ at $4971.5 \mathrm{eV}$ (sol), and $4971.7 \mathrm{eV}$ (gel), and finally, B at $4973.5 \mathrm{eV}$ (sol), $4973.8 \mathrm{eV}$ (gel). These positions are very close to those of anatase (4968.6, 4970.4, 4971.6, and $4973.8 \mathrm{eV}$, indicating that the local symmetry around $\mathrm{Ti}$ atoms is similar $\left(D_{2 d}\right.$ group). However, in anatase, A2 appears as a shoulder of $\mathrm{A} 3\left(I_{\mathrm{A} 2} / I_{\mathrm{A} 3}=0.6\right)$.

(42) Farges, F.; Gordon, E.; Brown, Jr.; Rehr, J. J. Phys. Rev. B 1997, 56, 1809. 

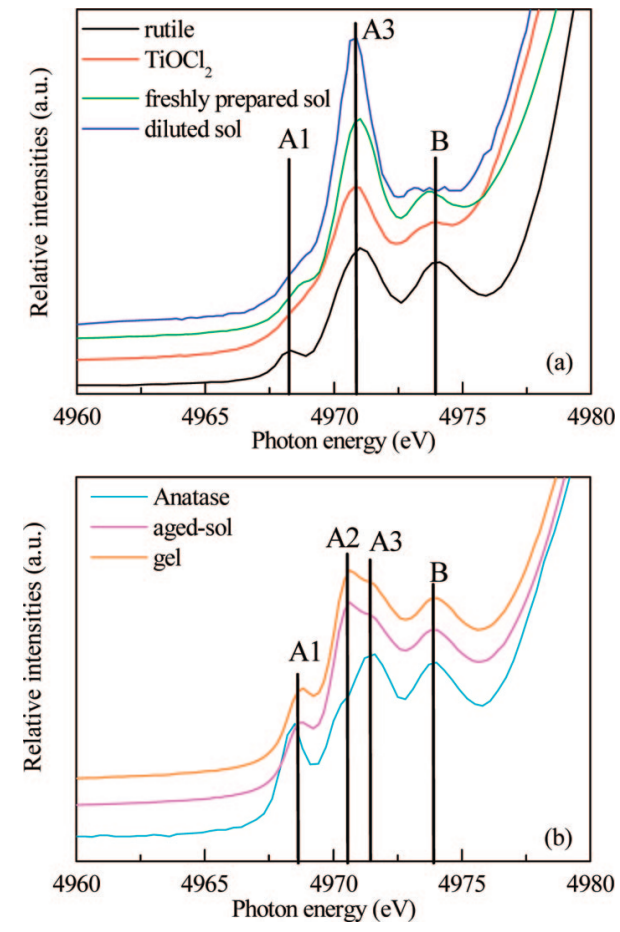

Figure 6. Titanium K-edge XANES spectra: (a) $\mathrm{TiO}_{2}$ rutile, $\mathrm{TiOCl}_{2}$, $<<$ TiDMF $>>$ freshly prepared sol $\left(\left[\mathrm{Ti}^{4+}\right]=1.42 \mathrm{~mol} \mathrm{~L}^{-1}\right)$ and diluted sol $\left(\left[\mathrm{Ti}^{4+}\right]=0.1 \mathrm{~mol} . \mathrm{L}^{-1}\right)$, (b) $\mathrm{TiO}_{2}$ anatase, $<<\mathrm{TiDMF}>>$ aged sol-gel with concentration $\left[\mathrm{Ti}^{4+}\right]=1.42 \mathrm{~mol} \mathrm{~L}^{-1}$.

(43) (a) Joly, Y.; Cabaret, D.; Renevier, H.; Natoli, C. R Phys. Rev. Lett. 1999, 82, 2398. (b) Danger, J.; Le Fèvre, P.; Magnan, H.; Chandesris, D.; Bourgeois, S.; Jupille, J.; Eickhoff, T.; Drube, W. Phys. Rev. Lett. 2002, 88, 243001-1-4.

(44) Luca, V.; Djajanti, S.; Howe, R. F. J. Phys. Chem. B 1998, 102, 10650.

(45) Hanley, T. L.; Luca, V.; Pickering, I.; Howe, R. F. J. Phys. Chem. B 2002, 106, 1153
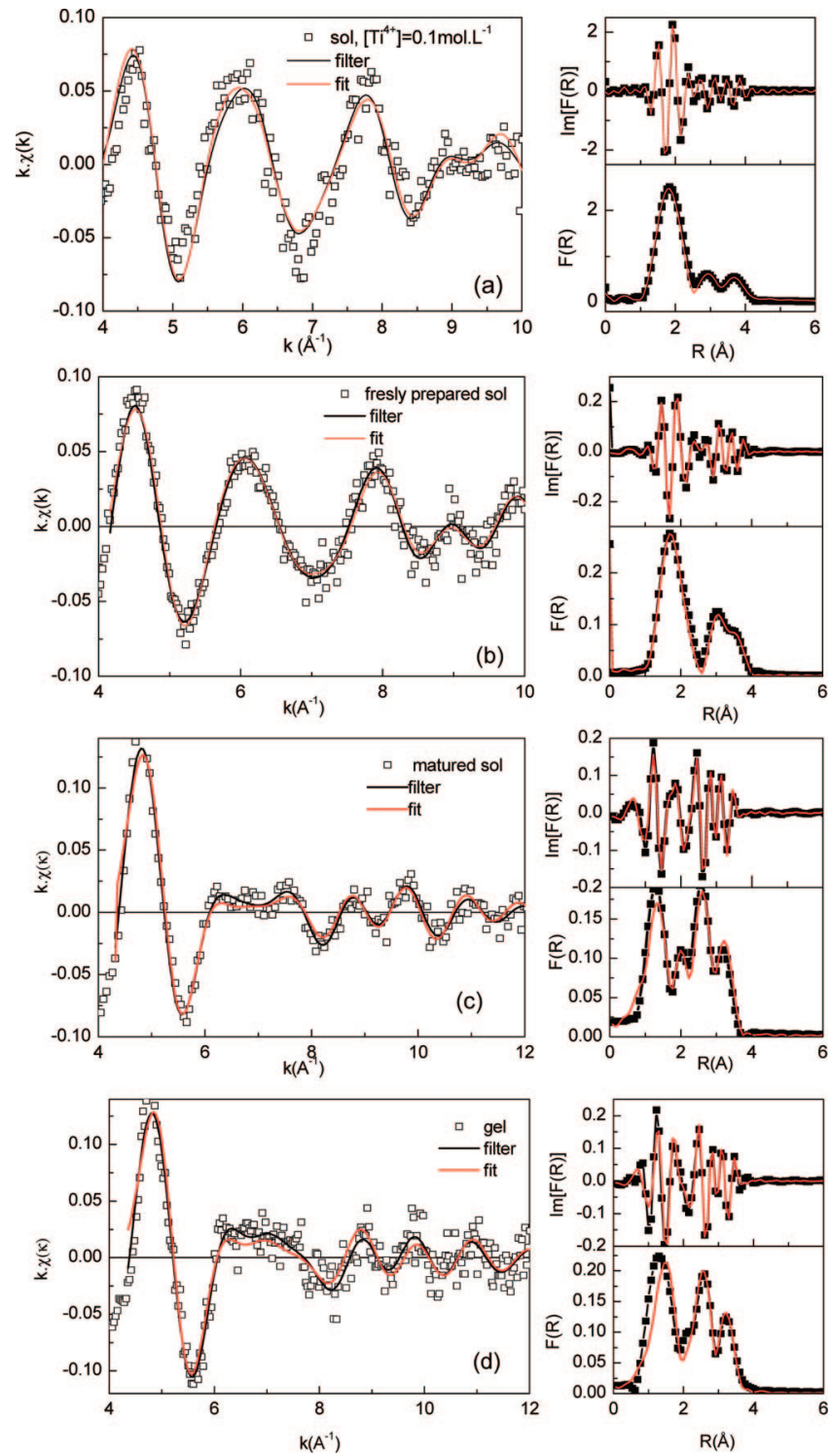

Figure 7. EXAFS spectra of $<<\mathrm{TiDMF}>>$ samples. Inverse Fourier transforms of experimental, filtered (in the 1.2-4 $\AA$ range), and calculated (left panels), imaginary part (right upper panel), and module of the Fourier transform (right lower panel) filtered and calculated signals: (a) diluted sol $\left(\left[\mathrm{Ti}^{4+}\right]=0.1 \mathrm{~mol} \mathrm{~L}{ }^{-1}\right)$, (b) freshly prepared sol,(c) aged sol, and (d) gel with concentration $\left[\mathrm{Ti}^{4+}\right]=1.42 \mathrm{~mol} \mathrm{~L}{ }^{-1}$. The FT are not corrected from phase shifts.

(c) aged sol and (d) gel also exhibit quite similar signals. The extracted signals of EXAFS spectra clearly differ from $\mathrm{a}$ and $\mathrm{b}$ to $\mathrm{c}$ and(d samples. The results of the best fit are summarized in Table 2. The inverse Fourier transforms of the experimental and calculated spectra can be compared in Figure 7(left); the comparison of the imaginary part and the module of the Fourier transform of the experimental and calculated spectra can be made from Figure 7(right).(a) Freshly Prepared Sols. The 6-fold coordinated titanium atoms of concentrated sol $\left(\left[\mathrm{Ti}^{4+}\right]=1.42 \mathrm{~mol} \mathrm{~L}^{-1}\right)$ are built from one short $(1.79 \AA)$ and five rather long $\mathrm{Ti}-\mathrm{O}$ distances, i.e., $2.15 \AA$ A. In a more diluted sol $\left(0.1 \mathrm{~mol} \mathrm{~L}^{-1}\right)$, the best simulation is obtained from one $\mathrm{Ti}-\mathrm{O}$ distance at $1.84 \AA$ and five $\mathrm{Ti}-\mathrm{O}$ distances at $2.19 \AA$ for the first neighbors. The shortest bond is typical of a $\mathrm{Ti}-\mathrm{O}$ bond observed in oxides $(1.86 \AA<d<2.03 \AA$ ), whereas the longest distance can be attributed to $\mathrm{Ti}-\mathrm{OH}$ or $\mathrm{Ti}-\mathrm{OH}_{2}$. Two $\mathrm{Ti}-\mathrm{Ti}$ 
Table 2. Refinement Results of EXAFS spectrum Performed at the Titanium K-Edge for Various $<<$ TiDMF $>>$ Transparent Sols and $\mathrm{Gel}^{a}$

\begin{tabular}{|c|c|c|c|c|c|}
\hline shell & element & $N(\mathrm{cf})$ & $\sigma\left(\times 10^{2}\right)(\AA)(\mathrm{f})$ & $R(\AA)(\mathrm{f})$ & $\Delta E(\mathrm{eV})(\mathrm{F})$ \\
\hline \multicolumn{6}{|c|}{ Diluted Sol with Concentration $\left[\mathrm{Ti}^{4+}\right]=0.1 \mathrm{~mol} \mathrm{~L}^{-1 b}$} \\
\hline 1 & $\mathrm{O}$ & $1.1(2)$ & 10 & $1.84(5)$ & 7.2 \\
\hline 2 & $\mathrm{O}$ & $5.0(1)$ & 10 & $2.19(5)$ & 7.2 \\
\hline 3 & $\mathrm{Ti}$ & $2.0(4)$ & 8.5 & $3.52(5)$ & 7.2 \\
\hline 4 & $\mathrm{Ti}$ & $2.0(4)$ & 7.5 & $3.77(5)$ & 7.2 \\
\hline \multicolumn{6}{|c|}{ Freshly Prepared Sol with Concentration $\left[\mathrm{Ti}^{4+}\right]=1.42 \mathrm{~mol} \mathrm{~L}^{-1 c}$} \\
\hline 1 & $\mathrm{O}$ & $1.3(6)$ & 11 & $1.79(5)$ & 7.7 \\
\hline 2 & $\mathrm{O}$ & $4.7(7)$ & 11 & $2.15(5)$ & 7.7 \\
\hline 3 & $\mathrm{Ti}$ & $2.0(2)$ & 8.5 & $3.48(5)$ & 7.7 \\
\hline 4 & $\mathrm{Ti}$ & $2.0(2)$ & 8.5 & $3.74(5)$ & 7.7 \\
\hline \multicolumn{6}{|c|}{ Aged Sol with Concentration $\left[\mathrm{Ti}^{4+}\right]=1.42 \mathrm{~mol} \mathrm{~L}^{-1 d}$} \\
\hline 1 & $\mathrm{O}$ & $3.0(6)$ & 10 & $1.89(5)$ & 2.5 \\
\hline 2 & $\mathrm{O}$ & $3.0(6)$ & 10 & $2.10(5)$ & 2.5 \\
\hline 3 & $\mathrm{Ti}$ & $3.0(6)$ & 8 & $3.17(5)$ & 2.5 \\
\hline 4 & $\mathrm{Ti}$ & $3.0(6)$ & 8 & $3.39(5)$ & 2.5 \\
\hline \multicolumn{6}{|c|}{ Gel with Concentration $\left[\mathrm{Ti}^{4+}\right]=1.42 \mathrm{~mol} \mathrm{~L}^{-1 e}$} \\
\hline 1 & $\mathrm{O}$ & $4.0(8)$ & 11 & $1.94(5)$ & 1.3 \\
\hline 2 & $\mathrm{O}$ & $2.0(4)$ & 11 & $2.14(5)$ & 1.3 \\
\hline 3 & $\mathrm{Ti}$ & $4.0(8)$ & 9 & $3.15(5)$ & 1.3 \\
\hline 4 & $\mathrm{Ti}$ & $4.0(8)$ & 9 & $3.37(5)$ & 1.3 \\
\hline
\end{tabular}

${ }^{a}$ cf, refined under constraint; f, refined parameters; $F$, fixed parameters; $N$, number of atoms at a distance $R$ from the central Ti atom for each shell; $\sigma$, Debye-Waller factor; $\Delta E$, shift in origin of energy. ${ }^{b} \rho=1.30 \times 10^{-2} ; \chi_{\mathrm{v}}{ }^{2}=2.3 \times 10^{-4}$ (see text). ${ }^{c} \rho=1.34 \times$ $10^{-2} ; \chi_{\mathrm{v}}{ }^{2}=1.9 \times 10^{-4}$ (see text). ${ }^{d} \rho=1.81 \times 10^{-2} ; \chi_{\mathrm{v}}{ }^{2}=3.9 \times$ $10^{-4}$ (see text). ${ }^{e} \rho=2.65 \times 10^{-2} ; \chi_{\mathrm{v}}{ }^{2}=7.4 \times 10^{-4}$ (see text).

distances have to be retained in order to account for the signal. The second neighbors are located at $3.48 \AA(N=2$, $N$ is the number of neighboring atoms) and $3.74 \AA(N=2)$ for $\left[\mathrm{Ti}^{4+}\right]=1.42 \mathrm{~mol} \mathrm{~L}^{-1}$ and at $3.52(N=2)$ and $3.77 \AA$ $(N=2)$ for $\left[\mathrm{Ti}^{4+}\right]=0.1 \mathrm{~mol} \mathrm{~L}{ }^{-1}$. Such distances agree well with those commonly encountered in the $\mathrm{ReO}_{3}$ type structure in which distorted $\mathrm{TiO}_{6}$ octahedra share corners. The distribution of the $\mathrm{Ti}-\mathrm{Ti}$ distances, $3.48-3.77 \AA$, originates from $\mathrm{Ti}-\mathrm{O}-\mathrm{Ti}$ tilt angles ranging from 145.5 to $180^{\circ}$.(b) Aged Sol and Gel. Assuming a distorted octahedral oxygenated environment, as before, the retained fit for aged sol and gel leads to three (four) $\mathrm{Ti}-\mathrm{O}$ distances at $1.89 \AA$ $(1.94 \AA)$ and three $(t w o) \mathrm{Ti}-\mathrm{O}$ distances at $2.10 \AA$ ( $2.14 \AA)$. As previously mentioned, these distances can correspond to $\mathrm{Ti}-\mathrm{O}$ and $\mathrm{Ti}-\mathrm{OH}$ or $\mathrm{Ti}-\mathrm{OH}_{2}$ bonds, respectively. Fitting the second neighbors of $\mathrm{Ti}$ atoms allows us to differentiate two pairs of Ti-Ti distances located at $3.17 \AA(3.15 \AA)$ and $3.39 \AA(3.37 \AA)$. The former agrees with octahedra sharing edges, whereas the longest is observed when octahedra are connected by corners. These results suggest that the $\mathrm{TiO}_{6}$ arrangement in aged sol and gel with $\left[\mathrm{Ti}^{4+}\right]=1.42 \mathrm{~mol}$ $\mathrm{L}^{-1}$ is different from that found in freshly prepared sols with the same concentration.

$X$-ray Diffraction. X-ray measurements, displayed in Figure 8, show that the polymeric sols and gel obtained in various concentration ranges remain poorly crystallized. For low concentrations of the sol samples $\left(\left[\mathrm{Ti}^{4+}\right]=0.1 \mathrm{~mol}\right.$ $\mathrm{L}^{-1}$ ), only two Bragg reflections are observed: a weak peak in the low-angle region, located at $d=14.23 \AA$ and a broad peak centered at $d \approx 3.7 \AA$. At higher concentration $\left[\mathrm{Ti}^{4+}\right]$ $=1.42 \mathrm{~mol} \mathrm{~L}^{-1}$, two main Bragg reflections also appeared for most of the aged sols and gels studied: an intense peak located at $d=19 \AA$ and an often rather broad peak located at $d \approx 3.6-3.7 \AA$. The aged sols and gels exhibit a quite

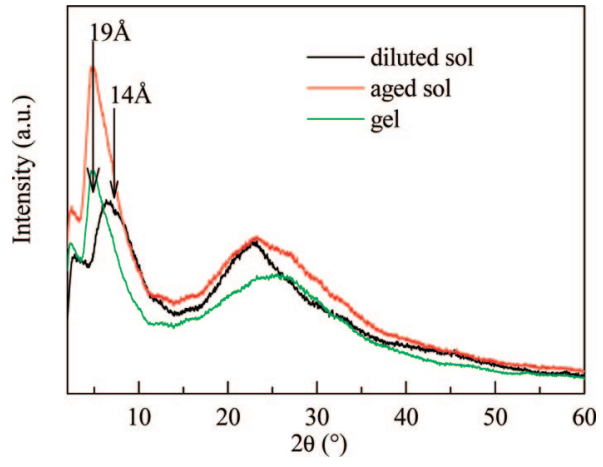

Figure 8. XRD patterns of $<<$ TiDMF $>>$ diluted sol with concentration $\left(\left[\mathrm{Ti}^{4+}\right]=0.1 \mathrm{~mol} \mathrm{~L}{ }^{-1}\right)$ and aged sol and gel with concentration $\left[\mathrm{Ti}^{4+}\right]=$ $1.42 \mathrm{~mol} \mathrm{~L}^{-1}$.
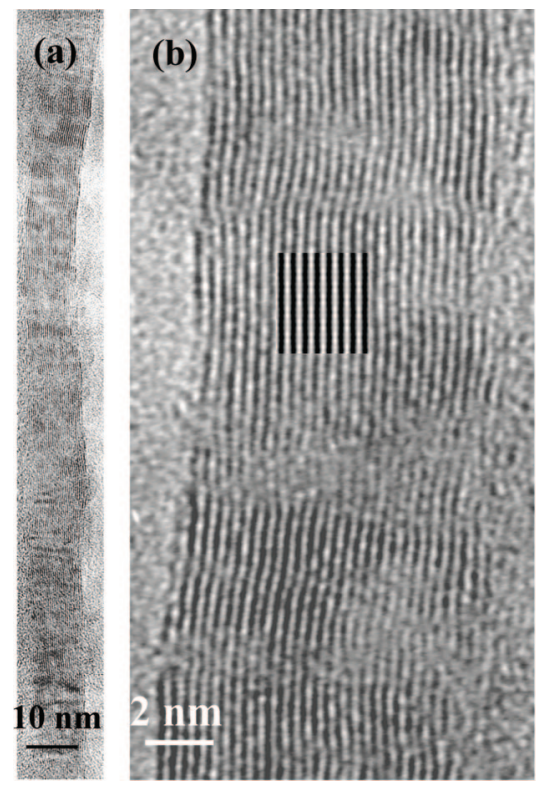

(c)

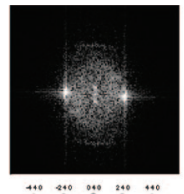

(d)

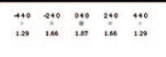

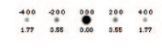

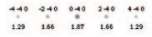

(e)

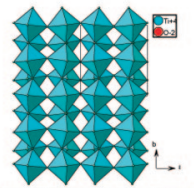

Figure 9. TEM studies of $<<$ TiDMF $>>$ diluted sol: (a) low-magnification image; (b) filtered high-resolution image along [001] showing the polymeric structure; the inset calculated image is for $3 \mathrm{~nm}$ thick foil at $85 \mathrm{~nm}$ defocus; (c) Fourier transform of the image; (d) calculated ED pattern with (001) zone axis; (e) structural model along [001]; (f) experimental image showing a digital print morphology.

similar XRD patterns. The presence of a low-angle reflection suggests that these compounds could adopt a lamellar structure.

Structural Models for $<<$ TiDMF $>>$ Sols and Gel. Because XAS and X-ray diffraction do not give sufficient information to elucidate the packing in the fibers at the symmetric level, the structure and morphology of sols and gel in various concentrations were investigated by transmission electron microscopy. The latter clearly demonstrates that these $<<$ TiDMF $>>$ compounds self-assemble into highly ordered polymers at the nanometer scale, and the highresolution images reveal the structures of the titania sols and gel. (a) $<<$ TiDMF $>>$ Sol $\left(0.1 \mathrm{~mol} \mathrm{~L}^{-1}\right)$. Figure 9 shows some electron micrographs of the weakly concentrated sol. The sol exhibits a ribbonlike morphology with a very regular shape and high aspect ratio (Figure 9a): length $180 \mathrm{~nm}$, width $9 \mathrm{~nm}$,and thickness $3 \mathrm{~nm}$ (deduced from the calculated image). The experimental image was processed in order to improve the observed contrasts and the filtered image is 
depicted in Fgure9b with the Fourier tansform (Figure 9c). The two-dimensional (2D) structure of the polymer consists of nanosized thin layers with a periodicity of $3.5 \AA$, deduced from the distance between the parallel dark striations on the filtered image. Among the numerous titanates with layered perovkite-type structures, only one can be retained with respect to the XAS and X-ray diffraction results. The two Ti-Ti distances at almost 3.5 and $3.75 \AA$ with both neighboring $\mathrm{Ti}$ atoms suggest that the structure is built from single layers as in $\mathrm{NaLaTiO}_{4}{ }^{46}$ Unfortunately, the relative stacking of layers in the perpendicular direction does not agree with the experimental contrast observed in HRTEM. The tetragonal symmetry disagrees with different $\mathrm{Ti}-\mathrm{Ti}$ distances, and the $P 4 / \mathrm{nmm}$ space group implies a shift of $(1 / 2,1 / 2)$ in the (110) plane from one layer to the other, leading to more homogeneous contrasts along the [100] and [010] directions. Consequently, the structural model chosen refers to $\mathrm{KFeF}_{4}$ layered perovkite (Figure 9e), which crystallizes in the orthorhombic system with the $P m 2_{1} n$ space group and matches with results found by XAS and XRD. Most likely, the structure consists of a layered arrangement of distorted $\mathrm{TiO}_{6}$ octahedra sharing corners in which each layer is stabilized by hydrogen bonds between water molecules and $\mathrm{Ti}-\mathrm{OH}_{2}$ bonds along a direction parallel to the long axis of the layers, i.e., the [010] direction. This conclusion is further supported by the fact that structures with very regular shape and high aspect ratio arise from a strong anisotropic growth process. Using a perovskite-like structure in projection along [001] (Figure 9e), the observed contrasts on the filtered image fit quite well with that calculated for a defocus value of 85 $\mathrm{nm}$ and a lamellar thickness $t=3 \mathrm{~nm}$ (inset of Figure 9b). The lack of contrast along the [010] direction, results from a $1.8 \AA$ periodicity of $\mathrm{TiO}$ atomic columns, which is close to the resolution limit. The calculated electron diffraction pattern (Figure 9d) in projection along [001] is in reasonable agreement with the Fourier transform image (Figure 9c). For the weakly concentrated sol, the inorganic part crystallizes in the orthorhombic system with the $P m 2{ }_{1} n$ space group and approximate cell parameters $a \approx 7.1 \AA, b \approx 7.5 \AA$, and $c \approx$ $14 \AA$. The proposed structural model does not preclude the presence of the Ti-OH bonds, $\mathrm{H}_{3} \mathrm{O}^{+}$, or other species inserted into the interlayer space. Interestingly, the rigid lamellar structure of Figure 9c can be rolled and transformed into an annular disk as in Figure 9f. The main structural features of both morphologies are retained with respect to the distances on electron diffraction patterns and the width of the layer $(9 \mathrm{~nm})$. The lamellar to disk transformation suggests that $\mathrm{TiO}_{6}$ octahedra undergo additional distortion with small tilts compared to the regular layered perovskite (Figure S2 in the Supporting Information). Assuming that the cohesion necessary for the stability of lamellar structures is provided by hydrogen bonds, the decreased amount of intercalated water molecules reduces the hydrophilic volume fraction and the transition from layer to disk structures occurs to minimize the interfacial energy between $\mathrm{Ti}-\mathrm{O}$ network and water molecules. Thus the digital print morphology can

(46) (a) Toda, K.; Kameo, Y.; Kurita, S.; Sato, M. J. Alloys Compd. 1996, 234, 19-25. (b) Byeon, S.-H.; Park, K.; Itoh, M. J. Solid State Chem. 1996, $121,430$.

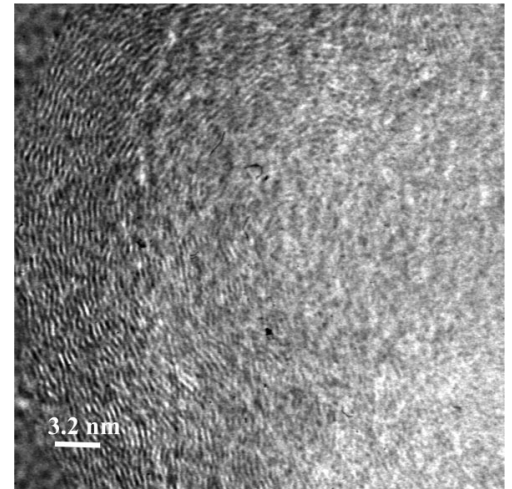

Figure 10. HRTEM experimental image of $<<$ TiDMF $>>$ aged sol and gel.

be explained as arising from breaking of some hydrogen bonds characteristics of rigid segment along [010].(b) Freshly Prepared $<<$ TiDMF $>>$ Sol. At higher concentration $\left(\left[\mathrm{Ti}^{4+}\right]=1.42 \mathrm{~mol} \mathrm{~L}^{-1}\right)$, the structure of freshly prepared sol further self-assembles into arrangements with shortrange order, which has not been evidenced during the HRTEM experiments. From XAS results, it is clear that the main packing motif is probably similar to the arrangement encountered in a diluted sol. That no structure could be isolated by TEM suggests that the extension of the 2D layers is limited in this case, probably because of the highly acidic medium during the first rapid step of hydrolysis. (c) $<<$ TiDMF $>>$, Aged Sol and Gel. For both samples, we observed long thin fibers, which form an entangled network. The experimental image (Figure 9) reveals that the structure of $<<$ TiDMF $>>$ gel seems to present a unidimensional character (1D): the polymer fibers are wound concentrically in the manner of a cotton ball. The presence of an important disorder in the direction perpendicular to the stacking of fibers appears on the electron diffraction pattern as two diffuse lenticular spots. The average periodicity, inferred from the spacing between fibers, is close to $3.5 \AA$. The effect of beam-exposure on the polymeric fibers leads, after a few minutes, to the coalescence of the TiO network and the generation of small crystallites reaching $\sim 10 \mathrm{~nm}$ in diameter. Their orientation disorder gives rise to diffraction rings in the Fourier transform spectrum. From an estimate of their intensity and a relative measurement of their position, one can identify the (101) and (004) planes of anatase (Figure $\mathrm{S} 3$ in the Supporting Information). This suggests that the crystallites mainly extend in the (010) plane. A similar effect to that of beam exposure is obtained upon heating a sol at a temperature higher than $70{ }^{\circ} \mathrm{C}$.In a first approximation and taking into account the previous XAS results, the structural model proposed is based on the $\mathrm{FeUS}_{3}$ type structure, which crystallizes in the orthorhombic symmetry with the $\mathrm{Cmcm}$ space group. The inorganic part of aged sol and gel is built from a single chain in which distorted $\mathrm{TiO}_{6}$ octahedra share edges (two short $\mathrm{Ti}-\mathrm{Ti}$ distances at 3.15-3.17 $\AA$ ). Such chains, running along [010], are linked together by sharing corners (two $\mathrm{Ti}-\mathrm{Ti}$ distances at 3.37-3.39 $\AA$ ) in the [100] direction, resulting in polymeric layers parallel to the (001) planes ( $a, b$ plane) (Figure 10). FT-IR analysis shows 


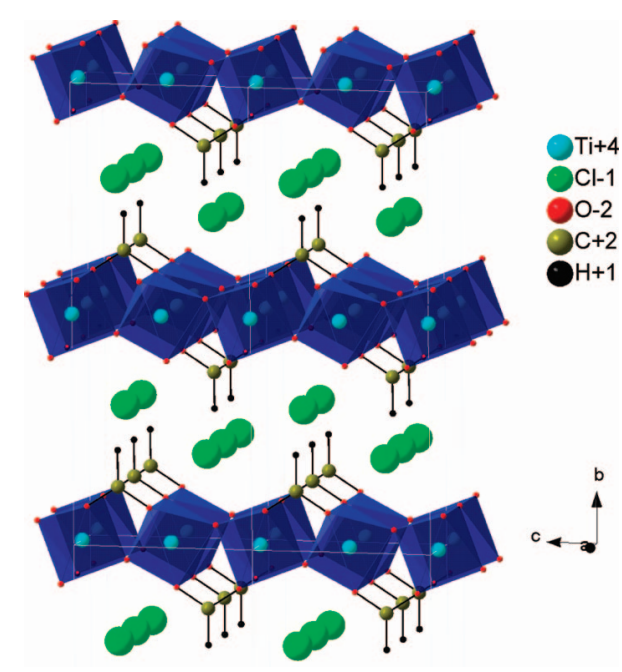

Figure 11. Structural model for aged sol and gel $\left(\left[\mathrm{Ti}^{4+}\right]=1.42 \mathrm{~mol} \mathrm{~L}^{-1}\right)$ that is based on the $\mathrm{FeUS}_{3}$ type structure.

evidence that the major part of the methanoate group, formed during the decomposition of DMF, is coordinated to $\mathrm{Ti}$ atoms either in a bidentate fashion or via ionic interaction. Because in a freshly prepared sol the methanoate species are mainly monodentate bonded to $\mathrm{Ti}$ cations, we infer that during aging, condensation of the inorganic framework leads to the formation of bridging unit between two 6-fold coordinated $\mathrm{Ti}$ atoms. These layers are stacked along the $c$ axis and held together by multiple hydrogen bonds between the apical $\mu_{2}$-oxygens of each octahedron and $\mathrm{CH}$ groups along the [001] direction, via chloride ions inserted into the layer. Because the inorganic arrangement was kept during the sol to gel transformation, the gel structure is stabilized by hydrogen bonds between DMACl groups and/or DMF. Hydrogen bonds can occur between a proton donor group $-\mathrm{CH}_{3}$, $\mathrm{Ti}-\mathrm{OH}$, and an electron-donating $\mathrm{Cl}$ atom or $C=\mathrm{O}$ group. This conclusion is further supported by the fact that in crystalline dimethylammonium chloride, each methyl group is hydrogen bonded to two chlorine atoms ${ }^{47}$ (Figure 11).

\section{Conclusion}

The route for polymer synthesis, starting from titanium oxo-salt precursor in DMF solvent, is a powerful method for the design of new nanomaterials. At this stage of investigation, the sol-gel formation involves a double hydrolysis process that operates on both organic (DMF) and inorganic $\left(\mathrm{TiOCl}_{2}\right)$ parts. Hydrolysis of DMF in $\mathrm{TiOCl}_{2}$ acidic medium leads to the formation of DMACl and $\mathrm{HCOOH}$, and at the same time, the consumption of hydrochloric acid enables a gentle control over the inorganic

(47) Lindgren, J.; Olovsson, I. Acta Crystallogr. 1968, 24, 549. polymerization. As a first step in our kinetic study of the highly concentrated sol, the DMF hydrolysis is mainly concerned and monodentate methanoate species are adsorbed onto the $\mathrm{Ti}-\mathrm{O}$ framework. Because of the low $\mathrm{pH}$ values, the sol consists of two phases, i.e. a continuous phase (DMF, DMACl, $\mathrm{HCOOH}, \mathrm{H}_{2} \mathrm{O}, \mathrm{HCl}$ ) in which the other phase, containing $\mathrm{Ti}-\mathrm{O} / \mathrm{OOCH}$ nanoribbons with octahedra sharing corners only as in $\mathrm{KFeF}_{4}$ arrangement, is dispersed. The increasing amount of DMACl and methanoic acid then induces a rapid decreasing in the acidity. In the second step, the $\mathrm{Ti}-\mathrm{O}$ framework slowly condenses to form aged sol and gel. The 2D structure contains octahedra sharing both edges and corners, on which bidentate methanoate species are adsorbed. After a thermal treatment at $70{ }^{\circ} \mathrm{C}$, the fibers form a three-dimensional network in the DMF/DMACl mixture, thereby turning the aged sol into a gel. It is worth noting that the growth of the layered structures is intimately correlated to the mono- or bidentate nature of adsorbed methanoate species and to the titanium concentration. The present study clearly shows that this one-pot process allows a careful control over the hydrolysis and condensation reactions because the gelation times of $\langle<\mathrm{TiDMF}\rangle>$ sols are of the order of days or months, depending on the thermal treatment. Therefore, the nucleation and growth mechanisms are well-separated. The size and structure of nanoribbons in sol-gel can be manipulated and controlled by adjusting the suspension $\mathrm{pH}$ and using suitable dispersants. These nanostructured sols and gel exhibit original optical and electronic properties that will be studied in the future.

Acknowledgment. A.R. is indebted to the Région Pays de la Loire for a grant. Dr. Jean-Luc Rehspringer, IPCMS-GMIStrasbourg; Dr. Fabrice Odobel and Gilbert Nourisson, LSONantes; and Dr. Anne-Marie Marie are thanked for their help in TG/MS, ${ }^{1} \mathrm{H}$ NMR, and TEM experiments, respectively. Dr. Françoise Villain (LURE, France) is thanked for contributions to XAS experiments and fitting. We acknowledge Desy (Deutsches Elektronen-Synchrotron) and Dr. Edmund Welter (Hasylab, Hamburg) for assistance during experiments (Projects I-04-041 EC and I-05-087 EC). This work was supported by the European Community-Research Infrastructure Action under the FP6 "Structuring the European Research Area" Program (through the "Integrated Infrastructure Initiative "Integrating Activity on Synchrotron and Free Electron Laser Science) and by the French Ministère de la Recherche through the ACI Energie and ACI Nanosciences. We also acknowledge the European Synchrotron Radiation Facility for provision of beamtime (Projects CRG 30-02-733 and CH-2220) and thank Dr. Hervé Palancher, Dr. Olivier Proux (beamline FAME), and Dr. Carmello Prestipino (beamline BM29) for assistance in XAS data collection.

Supporting Information Available: Figures $\mathrm{S} 1-\mathrm{S} 3$ and an additional table (PDF). This material is available free of charge via the Internet at http://pubs.acs.org.

CM702531Q 